\title{
London Underground Map
}

2018 erwarb die WLB ein Exemplar der Erstausgabe des berühmten Londoner U-Bahn-Plans von 1933.

Die ersten U-Bahn-Pläne von London erschienen ab 1906. Sie stellten die verschiedenen U-BahnLinienverläufe in unterschiedlichen Farben dar und orientierten sich ungefähr an den geographischen Gegebenheiten. Anfänglich enthielten sie auch noch Darstellungen der Oberfläche, also Elemente eines "normalen" Stadtplans. Mit dem ständigen Ausbau der U-Bahn wuchs die Unübersichtlichkeit dieser Art von Plänen, insbesondere in der Darstellung des Stadtzentrums, wo die U-Bahn-Stationen nah beieinander lagen. Der britische technische Zeichner und Graphikdesigner Henry Charles - genannt Harry - Beck (1902-1974) entwickelte 1931 eine ganz neue Art der Darstellung. Der gesamte Plan wurde stark schematisiert. Die Linien wurden praktisch nur noch waagerecht, senkrecht oder im $45^{\circ}$-Winkel geführt. Außerdem veränderte Beck die Abstände zwischen den einzelnen Stationen: Weiter auseinander liegende Stationen - insbesondere in den Außenbezirken - rückten näher zusammen, während näher beieinander liegende Stationen im Stadtzentrum auseinandergerückt wurden. Das Zentrum betrachtete man somit wie durch eine Lupe. Diese Art der Darstellung hielt sich überhaupt nicht mehr an die topographischen

Gegebenheiten, sondern schuf eine in dieser

Beziehung vollkommen verzerrte Darstellung, die

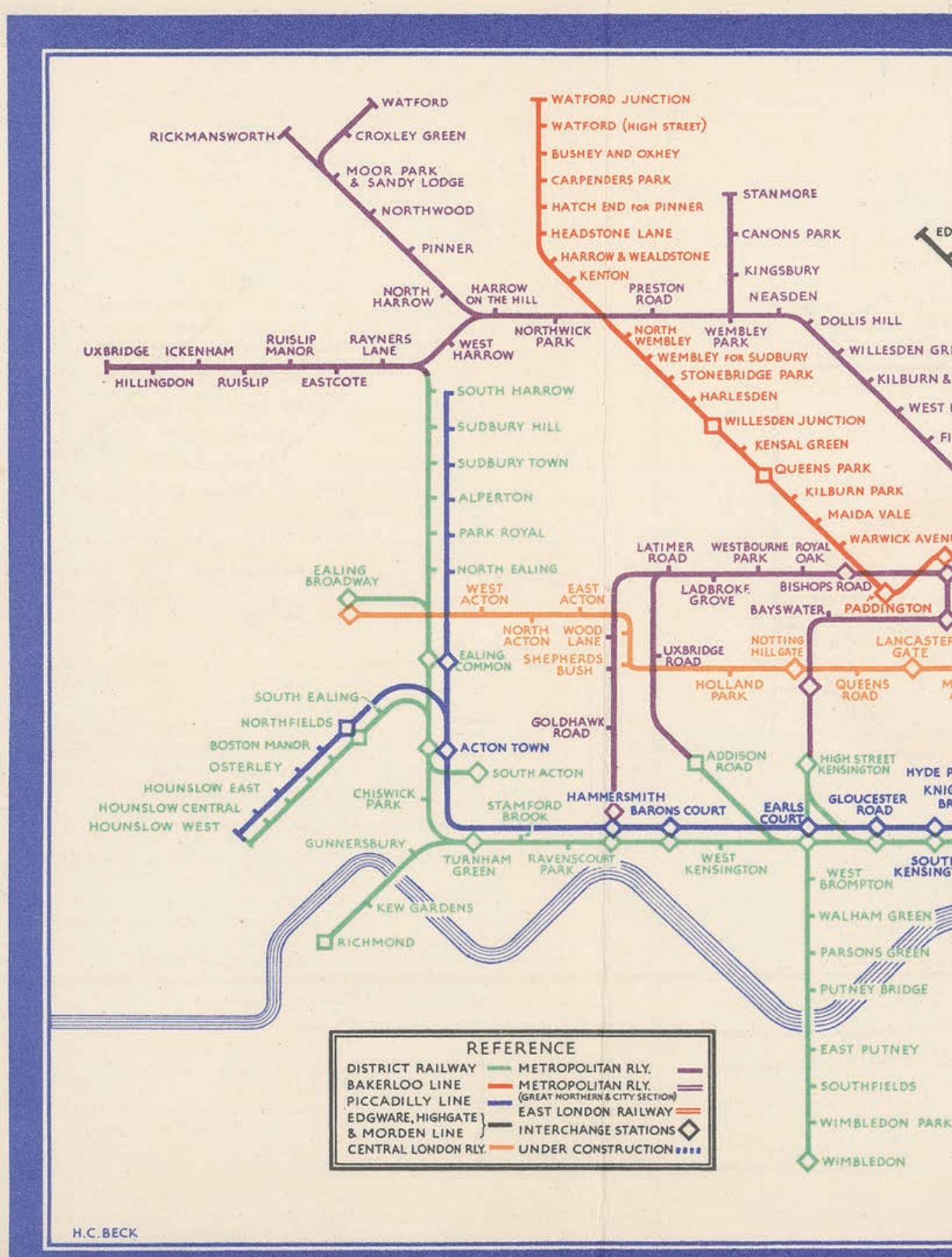

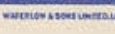

jedoch für die Zwecke des U-Bahn-Fahrens durch Übersichtlichkeit und Klarheit glänzte. Wie bei den früheren U-Bahn-Plänen wurden die verschie- 
